\title{
The Vertical Scar Mammaplasty in Gigantomastia: Retrospective Study of 115 Patients Using the Modified Lejour Technique
}

\author{
Aldo Mottura, M.D. \\ Centro de Cirugía Estética, Córdoba, Argentina
}

After reading this interesting paper and reviewing the tables, I want to highlight a few points in addition to the conclusion of the authors. Concerning the final vertical scar, $33(18.6 \%)$ of the 177 breasts presented in Table 5 ended up with an inverted T-scar. Also as shown in Table 5, $35(66 \%)$ of the 53 breasts that had surgery were left with an inverted T-scar.

In some instances, it is reasonable to finish with a small horizontal scar, but rates of $18 \%$ for the moderate glandular resection and $66 \%$ when the resection exceeded $1,000 \mathrm{~g}$ seem to be high. From a total of 230 $(177+53)$ breasts, $68(33+35)$ were left with an inverted T-scar, or 1 out of 3 . This deserves a different interpretation.

As I see it, a vertical mammaplasty is one in which the surgery finishes with a vertical scar. If the surgery finishes with an inverted T-scar, the technique is not vertical anymore and should not be reported as such. That means simply that many procedures denoted as vertical were not vertical but inverted $\mathrm{T}$ techniques.

Another point to be noted in Table 5 is that if a vertical technique was planned and had to be finished with an inverted T-scar, there was something wrong with the original plan. If the surgeons had planned these cases as simple inverted $\mathrm{T}$ techniques, they would have had the same result. The surgery could have been started with an inverted $\mathrm{T}$ technique in mind. In that case, this study would have shown different results. It is very common to hear that the surgeon, in finishing the vertical technique, to shorten the procedure, ends the surgery with small horizontal scars. Plastic surgeons often indicate that they are

Correspondence to Aldo Mottura M.D.; email: Amott@ esteticamottura.com doing "only vertical techniques," when in many cases, they in fact are doing inverted $\mathrm{T}$, or $\mathrm{L}$ or $\mathrm{J}$ techniques. With regard to the same topic, the report does not mention the length of "the small horizontal scars" of the inverted T, an important omitted detail.

Concerning complications, Table 1 shows that the rate for immediate and late complications was $38.98 \%$ for a glandular resection of 500 to $1,000 \mathrm{~g}$ ( $\mathrm{n}=177$ and 69-complications) and $35.84 \%$ for a resection exceeding $1,000 \mathrm{~g}(\mathrm{n}=53$ and 19 complications). Furthermore, Table 4, again summing immediate and late complications, shows that the rate for complications was $85 \%$ for patients between the ages of 21 and 40 years $(n=58$ and 49 complications) and $73.68 \%$ for patients older than 41 years ( $\mathrm{n}=38$ and 28 complications). Table 3 sums the immediate and late complications among smokers ( $\mathrm{n}=46$ and 22 complications 22) and shows the percentage to be $47.82 \%$.

Judging from the experience of senior plastic surgeons that I am sure have mastered this technique better than any other plastic surgeons, the complication rates in these three tables still seem high to me. The vertical technique has not yet been accepted worldwide due to the high rate of problems and the unpredictability of the results [1]. In my opinion, these two arguments were demonstrated in this article.

\section{Reference}

1. Rohrich R, et al.: Current preferences for breast reduction techniques: A survey of Board-certified plastic surgeons 2002”. Plast Reconst Surg J 114:1724-1733, 2004 